\title{
Problem Solving: Creative Management Mode of University Teaching
}

\author{
Huafang $\mathrm{Mao}^{1, *}$ \\ ${ }^{1}$ College of Educational Science, Taizhou University, Taizhou, Jiangsu 225300, China \\ *Corresponding author.Email:660373@tzu.edu.cn
}

\begin{abstract}
The management mode and characteristic of teaching should be consistent with the teaching mode and characteristic. Universities should take teaching as the center. As the teaching is one-off and creative, the university teaching management should also be creative. Problem solving mode is a creative mode for university teaching management, including three links of establishing goals, finding problems and solving problems.
\end{abstract}

Keywords: University teaching, Management mode, creativity, Problem solving.

\section{INTRODUCTION}

Management activities generally have two modes, namely, maintenance management mode and creative management mode. Maintenance management mode refers to the management behavior repeated year after year since the establishment of the management system in the actual management activities. Creative management mode refers to that in the actual management activities, on the one hand, the established management system is implemented; on the other hand, due to the complexity of the managed objects, the rationality of the existing system is constantly examined in the operation of the existing system, at the same time, new problems in management activities are constantly found, and then new solutions are put forward, new rules and regulations are formulated to improve the management behavior of management activities. University teaching management belongs to creative management. Firstly, university teaching is the central work of all university activities; Secondly, teaching is a creative work; Thirdly, the basic spirit of the university lies in creation.

\section{TEACHING: THE CENTER OF UNIVERSITY WORK}

The development of higher education has stepped into the stage of popularization. In the stage of mass higher education, the philosophy of university activities has changed, which makes the order of the two most basic functions of university "teaching and research" changed. University activities have changed from emphasizing scientific research achievements to emphasizing education and teaching quality, and teaching has become the central task of university activities. "Higher education is also education, and has the general characteristic of education." "For higher education, it is not only required to study and research knowledge, but also to educate people." [1] Therefore, the university of higher education is still a school, and focuses on education and teaching. At the same time, the popularization of higher education strongly impacts the original order relation between teaching and scientific research in colleges and universities, and changes the order direction. In the popularization stage of higher education, universities shifts from emphasizing higher learning to emphasizing higher skills. Therefore, "many people believe that in the popularization stage, the number and status of students are enhanced and improved in higher education institutions, and the status of teaching will naturally rise." [2]

Seemingly, for "scientific research — teaching" and "teaching — scientific research", it merely makes the adjustment of word order in form, however, it contains the transfer of the center of university activities, that is, from taking scientific research as center to taking teaching as the center. This change is mainly based on the following reasons. Firstly, from the purpose of university, 
university, as an educational institution, cultivates integrated man. Cultivating people and integrated people is originally contained in the original starting point of the universities. Because the cognitive function of the university in elite stage has been diluted, "cultivating people" can only be highlighted in the ideal of mass higher education. Universities should emphasize that cultivating people is the consensus of current higher education researchers and higher education practitioners. Yang Shuzi often says to his students, "what are you going to do in universities? I think there are three reasons. First, it is necessary to learn how to be a man; Second, it is required to learn how to think; Third, it is important to learn to master the necessary knowledge and the ability to use knowledge. These three are inseparable, completing with each other." [3]. Knowledge is the result of human cognitive activity. Cognition can be divided into three levels: the first level is the object of cognition, the second level is the way of cognition, and the third level is the value and ethics behind the way of cognition. These three levels all exist in the result of cognition in their own unique ways, that is, knowledge not only contains the object of "cognition" and "knowledge", but also includes the way of "cognition" and "knowledge", and the value and ethics behind "cognition" and "knowledge". Therefore, to cultivate man is to impart knowledge, which is the chief and best material for cultivating a integrated man. At present, higher education strongly advocates the mutual penetration of arts and sciences, the essence of which is that different types of knowledge contain different values and ethics, and people can obtain complete value judgment and sound personal ethical consciousness needed by the society through learning different knowledge, which is conducive to the cultivation of a integrated person. Secondly, from the perspective of training objectives, university education and teaching in the popularization stage should be oriented towards occupation. The so-called "occupation" means that university education and teaching must ensure that the "products" of higher education activities can find a "market" and adapt to this "market", which cannot be "unsalable", otherwise it will be a social waste and cause social unrest. With the science and technology and management revolution, modern industrial society has established a huge system based on bureaucracy and division of labor. Its core principle in the economic field is "benefit maximization". Through social division of labor, social members are assigned to different production departments according to different roles, and management and operation are more efficient through the establishment of bureaucracy. Industrial society emphasizes the role of technical expertise in solving social problems. In this highly organic society organized by functions and abilities, the corresponding university education has no choice but to establish an industrialized training mode according to the requirements of social division of labor. Professional education has become the only choice for universities. This requires the docking between university and society, and what the most important is to pay attention to imparting knowledge and skills simultaneously in teaching process, and teaching ideas, teaching methods, teaching content and so on become the focus of higher education management. In the extreme, the popularization of higher education strengthens the status of students as consumers of higher education. In Altbach's opinions, "students increasingly regard higher education as a better way to obtain better employment, increase income and social mobility." [4] Thirdly, from the perspective of training process, in the order relation of "teaching scientific research", the "academic freedom" should be transformed into "learning freedom", which determines that the methods and approaches adopted in the process of cultivation will be inconsistent with that of the tradition. Generally speaking, according to the classification of knowledge, the university training process usually adopts three forms: theoretical teaching, experimental teaching and social practice. Theoretical teaching enables students to master professional theory; experimental teaching aims to provide students with the possibility of innovative experiments by mastering the basic professional experimental skills, providing professional theoretical knowledge and experience; and social practice allows students to participate in professional practice activities to accumulate rich work experience and better combine theoretical knowledge and laboratory operation with real work scenes, constructing a bridge between the classroom and society. However, in the process of popularization, students' theoretical learning should not be limited to a certain professional field. Due to social changes, the era of "one career for life" has come to an end for most members of society. With the adjustment of economic structure and the emergence of new industries, every member of society must have lifelong learning ability and master a variety of knowledge and skills. "In order to meet the different interests of students, universities should also provide more elective courses. More and more students choose courses 
according to their own interests and social needs, rather than following the internal logic of the knowledge system under the guidance of teachers." [2] This requires that universities offer more courses, such as "course supermarkets". And then, students can select courses freely.

\section{CREATIVITY: THE ESSENTIAL ATTRIBUTE OF TEACHING}

Bruner once said that teaching is a creation every day and every hour. Every lesson of teachers, even every teaching behavior in each lesson, is "single-use", it is "impossible for teaching to step into the same river twice". When teaching the same teaching contents, teachers may have different students; when teaching the same students, teachers would teach different contents. For some reasons, the same lectures are given to the same person, which is no longer simply "copying". In reality, teaching is "single-use", but in possibility, teaching is characterized by intentionality, which determines that teaching must be creative. Without the creativity, it is impossible to accomplish intentionality through being one-off. Firstly, it is required to establish a "teaching relationship" before real teaching and learning activities, and "creativity" should represent teaching behavior at the relationship level and generation level.

"Creativity" represents the attribute on the relationship level of classroom teaching behavior. The so-called "creation" refers to the behaviors, such as "coming up with new methods" and "making new things". "Classroom teaching is creative". This is not a factual description, but a rational appeal. In other words, teaching behavior should be creative. Only creative teaching behavior is effective and can best express the teaching behavior of main body significance of teaching. "From the perspective of teaching ontology, teaching and learning are the attributes of the subject rather than itself. As attributes, on the one hand, teaching and learning are respectively attached to their own subjects, belonging to different attributes of teachers and students; on the other hand, these two contain and depend on each other. Each takes the other as the premise of its own existence, cooperates with each other according to the state of the other, and then extends to the subject itself." [5] That is to say, there are "teachers" and "students" as social roles, and they are also engaged in so-called "teaching activities", which does not mean that they are engaged in "teaching" and "learning" activities. The so-called "teaching activities" in the actual classroom may not be the real "teaching", because the real "teaching activities" should occur when "teaching" and "learning" exist at the same time. The attributes of "teaching" and "learning" as two subjects of classroom activities do not cover all the subjects, but only indicate a state of the subject at a certain time or on a certain side. Only teachers' behavior of "teaching" can promote students' behavior of "learning", and only students' behavior of "learning" can stimulate teachers' behavior of "teaching", which can be regarded as "teaching and learning" behavior. This means that "classroom teaching" requires teachers or students to actively participate in activities, and "being initiative" means that teachers and students should carry out creative teaching and creative learning in teaching and learning. From the perspective of relation attribute, creative "teaching" and "learning", or creative classroom teaching behavior, occurs in the dynamic process of classroom activities, and the creativity in the dynamic process is different from the thoughtful creativity in the static process. Deliberate creativity in static processes can withstand logical analysis. For creativity in static process, the behavior represented can be algorithmized. Creativity in the dynamic process may not stand up to withstand logical analysis, but creative behavior is intended by reason, and it is the result of rational thinking on the dynamic reality. This choice is based on the analysis, identification and insight of dynamic situations. Therefore, it is the result of using teaching wisdom.

"Creativity" represents the attribute on the generation level of classroom teaching behavior. Teachers have intention to "teaching" and students have intention to "learning", which is only a prerequisite for the real teaching activities. It is not enough for the actual teaching activities to only have the intention of "teaching" and "learning". The further problem is on how the intention of "teaching" and "learning" conform to each other in the specific teaching behavior, that is, the issues on "how to teach", "how to learn" and "how to relate". This is a question of working backwards for educational purposes, otherwise it is difficult for classroom teaching to fulfill "dual responsibilities at two levels". The goal of classroom teaching is "responsibility" rather than "task", and the completion of "task" only lies in "operating procedure", that is, it belongs to methodology. Once the "procedure operation" is completed, the "task" will be finished, which can be said to be a purely objective activity process. However, on the 
one hand, "responsibility" always means "task", more importantly, on the other hand, it also means "meaning", and "meaning" is "generated" rather than "taught". Therefore, "responsibility" depends not only on "operating procedures" (i.e. methodological guidance), but also on "generative art" (i.e. creative guidance) to realize the "meaning" requirement. The main reason why "generation" is combined with "art" is that it is different from "program" in "method". Pure "art" has a kind of "formative power" [6]. Accordingly, it can be said that "method" only has "make power". This "formative power" of classroom teaching behavior is a powerful expression of creativity. However, the artistic expression with formative power "is not composed of passive perception, but a perceptual way and process." And "the nature of this process is not purely subjective, on the contrary, it is still objective." Therefore, in the specific situation of classroom activities, this "formative power" of teaching behavior is the result of the combination of the objective situation of the classroom and the subjective ability of teachers, the perfect combination of "moral and aesthetic judgment" and "scientific rationality dominated by technical rules" in the real sense, rather than "creating opposition" between them [7], that is, the expression of teachers' practical wisdom.

\section{PROBLEM SOLVING MODE: CREATIVE MANAGEMENT OF UNIVERSITY TEACHING}

Teaching is the central work of university activities, and the development of teaching represents the development of the school. Therefore, the management level of teaching determines the level of the school. At the same time, teaching is creative work. The creativity of teaching determines that the management of creative activities must be creative, otherwise it is difficult to deal with the managed objects, let alone the development of the school. These two determine that university teaching management is a creative management work.

Problem solving mode is a creative management mode. The so-called problem-solving mode means that in the university teaching management activities, the problem-centered management is carried out. Problem solving mode generally includes four basic steps of finding problems, establish a problem-solving mode, running and debugging the mode, improving the mode. The link of "problem finding" in teaching management mainly comes from two aspects. First, it is required to find the links that are not running smoothly and find the problems in the established conventional management activities; Second, through the observation of the actual teaching activities, it is necessary to find the management that is not in place in the actual teaching activities. In the actual teaching management activities, the most common phenomenon is as follows. Managers pay more attention to the "first" type of problems, and the problems appear in "our eyes" to a certain sense. The "second" type of problems is problems that managers do not pay attention to or even ignore. "It's better to save trouble." Even managers don't know how to solve it, and how to properly and satisfactorily solve it is uncertain. Therefore, this kind of problems is not in the vision of managers. As for the link of "establishing problem solving mode", it is necessary to start with the problem finding, analyze the actual causes of the problems, and draw the relationship diagram between causes and phenomena. Phenomena are usually induced by multiple causes, and then all causes should be put into the theoretical framework. And it is better to clarify the relationship between causes logically, and further construct the solution mode. As for the link of "running and debugging mode", the mode that has been constructed theoretically or logically is like an "armchair strategist". The efficiency must be observed in practice. If it is effective in the process of theory and practice, the model is reasonable. If it is invalid or the effect is not ideal, the problem and the conflict between theory and practice should be found out, and then the model should be modified. The "perfect mode" means that the mode tested by practice must be revised and improved in theory, and finally become a conventional system. Therefore, it is necessary to pay attention to three links in the application of problem-solving mode in teaching management. These three links are objective setting, problem discovery and problem solving.

\subsection{Objective Setting}

Any human practical activities are activities guided by objectives. Only by determining more reasonable management objectives can we better carry out scientific management of colleges and universities, so it is necessary to adopt objective management. The so-called objective management is a management method that requires the upper and lower levels of teaching managers, relevant school members and teachers to jointly formulate and implement objectives, and carry out evaluation, 
reward and punishment activities according to the implementation results of objectives, so as to gradually realize "self-control". This management method has three meanings. First, the objective is the result jointly agreed by relevant members and departments, which determines the tasks, responsibilities and sub-targets that each department and individual should undertake; second, taking these general objectives and subobjectives as the basis for units and individuals to carry out activities, all activities of the school teaching management department are carried out around the achievement of these objectives and the objectives should be achieved by performing their duties; third, it is better to measure and evaluate individuals or departments based on their respective objectives. Objective management is a comprehensive method integrating planning function and control function, emphasizing precontrol through objectives in advance; managers shall exercise self-control during the process; and it is required to focus on assessment of results afterwards. At the same time, the establishment of the general objectives of university teaching management should be forward-looking.

\subsection{Problem Discovery}

The determination of objectives is the first step in the development of management activities. Objective is only a development blueprint and a thing with the characteristic of "armchair strategist". To achieve objectives, it is necessary to put them into action and combine objectives with reality. In this combination process, there is bound to be the opposition between realistic uncertainty and transcendence of objectives, which is the problem to be solved in management activities. The so-called problem discovery is to find the difference between goal transcendence and realistic uncertainty in management activities.

In the actual management activities, human beings can take a variety of ways and methods to find the contradiction between objectives and reality due to the guidance of objectives. In the actual management of higher education, most colleges and universities adopt experience management. The prerequisite for "experience" to play a role in management activities is the "similarity" of things, and the "similarity" of things has dual characters. On the one hand, "similarity" can provide people with thinking about new things. For example, the transformation thought and transformation ideology in scientific research are carried out by using the "similarity" of things; on the other hand, "similarity" only stays on the surface of things, that is, "similarity" is not the essential attribute of things. Therefore, people will often make wrong decisions and solutions because they don't grasp the essence of things with the use of "similarity" of things. In addition, colleges and universities will adopt administrative management. One of the most fundamental reasons for the "administrative management" mode is that manager starts from the subjective. The objectives in "administrative management" come from the "head" of managers or others. For example, seeing how the brother schools manage in the terms of personnel or teaching, the school will do the same thing in the corresponding field. The management objectives determined in this way are not refined from the reality of their own school. Such objectives are unrealistic and blind. These two management modes are often used in the practice of higher education, and have certain disadvantages.

In the problem-solving mode, institutional research methods can be used to find the problems in practice due to goal guidance. Institutional research is a new thing. Therefore, it is required to tell people what institutional research is and what its unique value is before it plays a role. Saupe, President of the American Academy Research Association, defines it as follows. "Academy research includes data collection, analysis and reporting, as well as designated work, which help colleges and universities operate." [8] This definition basically positions academy research as data collection, analysis and reporting. This means that the problem-solving management mode should be carried out with institutional research methods, and two aspects should be paid attention to in finding problems. First, institutional research needs someone to collect the information of all aspects of school work in order to understand how the school operates; second, institutional research has established that its work center is to collect, analyze and sort out school operation data. The management mode of colleges and universities to solve the problem is based on "evidence management". Collecting "evidence" means that the school operation data is the basis of management. Without the system data of school operation, it is impossible to carry out effective management.

Through long-term and systematic collection, classification, sorting, research and reporting of school operation data, the management efficiency of the school can be improved. The larger the school is, the more necessary the work is and the 
more remarkable the effect is. The school sets up a special organization to systematically and comprehensively collect all aspects of operation data, find problems in management, find the opposition between the school's development objectives and the school's objective reality, and then solve these opposites. Only in this way can the research of colleges and universities play the role of scientific management.

\subsection{Problem Solving}

After the problem is found, the solution to the problem needs to be put forward. The solution to the problem can usually be put forward in the forms of administrative meeting, small seminar or small hearing. The executive meeting is presided over by the president or the vice president of the department in charge of the problem. All functional departments and relevant individual organizations related to the problem participate in the joint meeting to discuss the solution of the problem and put forward the steps to solve the problem. At the small seminar, it will organize relevant experts, school leaders, relevant functional departments and other staff to discuss problem solutions, and then submit the solution to school leaders, which will be approved by school leaders. The relevant departments and personnel should implement them. At the small hearing, it is required to invite and welcome people from all walks of life to discuss the solution to the problem in an open form. The invitees should be representative and listen to the suggestions put forward by the representatives. Then the leading group of the meeting makes a plan, submits it to for approval, determines the plan, submits it to the school for filing, and instructs the relevant functional departments to implement it.

The form of executive meeting has high timeliness in solving problems, and is suitable for daily work or solving problems irrelevant to the overall situation. The form of small seminars is usually applicable to solving far-reaching issues with great impact, such as school development planning, teaching management system, financial policy and system. Hearings can be used to solve problems related to personal interests and local interests. The efficiency of small seminars and hearings is relatively low, but the management is relatively stable and strong.

The solution to the problem is only a document. If people want to know the real value and rationality of the solution, it is necessary to give necessary feedback after the implementation of the solution. Feedback has two functions. First, it can summarize whether the problem-solving methods have application value and whether they can be used for reference in future work; second, it is necessary to see whether the problems to be solved are completely solved and whether there are some omissions. If the problems are not completely solved or there are omissions, necessary remedies must be made. Finally, the results of problem solving should be made public and subject to the supervision of all teaching staff and students.

\section{CONCLUSION}

In universities, the methods of talent training mainly include classroom teaching, scientific research and social service. However, classroom teaching, or teaching for short, is the most popular and commonly used way at present, especially in newly-built local undergraduate colleges and universities. Therefore, strengthening the management of teaching has become the key to the quality of talent training. Teaching is a "one-off" and creative activity, and teaching management should also be creative. And it is necessary to put forward solutions in the face of new environment, new situation and new problems. Therefore, the problem-solving mode is a basic mode of innovative management of teaching.

\section{AUTHORS' CONTRIBUTIONS}

This paper is independently completed by Huafang Mao.

\section{REFERENCES}

[1] Wen Fuxiang. A Discussion on the Basic Characters of Higher Education [J]. Peking University Education Review, 2007 (2): 4145. (in Chinese)

[2] Xiang Xianming. The transformation of university teaching concepts in the process of popularization $[\mathrm{J}]$. Journal of Higher Education, 2004 (1): 75-79. (in Chinese)

[3] Yang Shuzi. Rule of virtue and personality nurturing $[\mathrm{J}]$. Journal of Higher Education, 2002 (3): 6-9, 50. (in Chinese)

[4] Philip G. Altbach. The logic of mass higher education [J]. Journal of Higher Education, 1999 (2). (in Chinese) 
[5] Zhang Guangjun. Embryological Observation of Instructional Existence: A New Perspective [J]. Educational Research, 2002 (2): 63-67, 96. (in Chinese)

[6] [Germany] Ernst Cassirer. Human Theory [M]. Gan Yang trans. Shanghai: Shanghai Translation Publishing House, 1998.189. (in Chinese)

[7] O’Neill, J. (1993) Ecology, Policy and Policy and Politics. Routledge. 118

[8] Joe Saupe. The Nature and Role of Institutional Research: Meno to a College or University. 1970.3. www.Air.org. Saupe, Chairman of the American Institutional Research Association. 